\title{
Morphometry of the Orbit in East-European Population Based on Three-Dimensional CT Reconstruction
}

\author{
Stanisław Nitek, ${ }^{1,2}$ Leopold Bakoń, ${ }^{3,4}$ Mansoor Sharifi, ${ }^{5,6}$ Maciej Rysz, ${ }^{7}$ \\ Lechosław P. Chmielik, ${ }^{5}$ and Iwona Sadowska-Krawczenko ${ }^{8}$ \\ ${ }^{1}$ Department of Otorhinolaryngology, Mazovian Hospital in Brodno, Center of Postgraduate Medical Education, \\ 8 Kondratowicza Street, 03-242 Warsaw, Poland \\ ${ }^{2}$ Institute of Rheumatology, Outpatient Department, 1 Spartańska Street, 02-637 Warsaw, Poland \\ ${ }^{3}$ 2nd Department of Clinical Radiology, Warsaw Medical University, 1a Banacha Street, 02-097 Warsaw, Poland \\ ${ }^{4}$ Military Institute of Aviation Medicine, 54/56 Krasińskiego Street, 01-755 Warsaw, Poland \\ ${ }^{5}$ Department of Paediatric Otorhinolaryngology, Medical University of Warsaw, 63A Żwirki i Wigury Street, 02-091 Warsaw, Poland \\ ${ }^{6}$ Department of Descriptive and Clinical Anatomy, Center of Biostructure Research, Medical University of Warsaw, \\ 5 Chałubińskiego Street, 02-004 Warsaw, Poland \\ ${ }^{7}$ Head and Neck Department, Maria Sklodowska-Curie Memorial Institute and Oncology Centre, 5 Roentgena Street, \\ 02-781 Warsaw, Poland \\ ${ }^{8}$ Faculty of Health Sciences, Ludwik Rydygier Collegium Medicum, Nicolaus Copernicus University, 13-15 Jagiellońska Street, \\ 85-067 Bydgoszcz, Poland
}

Correspondence should be addressed to Stanisław Nitek; stanislawnitek@wp.pl

Received 15 May 2015; Revised 8 September 2015; Accepted 30 September 2015

Academic Editor: Luis-Alfonso Arráez-Aybar

Copyright (c) 2015 Stanisław Nitek et al. This is an open access article distributed under the Creative Commons Attribution License, which permits unrestricted use, distribution, and reproduction in any medium, provided the original work is properly cited.

Objectives. To determine safe distances within the orbit outlining reliable operative area on the basis of multislice computed tomography (MSCT) scans. Patients and Methods. MSCT of orbits of 50 Caucasian patients (26 males and 24 females, mean age 56) were analysed. Native scans resolutions were in all cases $0.625 \mathrm{~mm}$. Measurements were done in postprocessing workstation with $2 \mathrm{D}$ and $3 \mathrm{D}$ reconstructions. The safe distances values were calculated by subtracting three standard deviations from the arithmetical average ( $X=$ AVG -3 STD). This method was chosen because this range covers $99.86 \%$ of every population. Results. The results of the measurements in men and women, respectively, are as follows (1) distance from optic canal to supraorbital foramen, mean $46,49 \mathrm{~mm}$ and $43,29 \mathrm{~mm}$, (2) distance from the optic canal to maxillozygomatic suture at the inferior margin of the orbit mean $45,24 \mathrm{~mm}$ and $42,8 \mathrm{~mm}$, (3) distance from the optic canal to frontozygomatic suture 46,15 mm and 43,58 mm, (4) distance from the optic canal to anterior lacrimal crest $40,40 \mathrm{~mm}$ and $38,39 \mathrm{~mm}$, (5) distance from superior orbital fissure to the frontozygomatic suture $34,06 \mathrm{~mm}$ and $32,62 \mathrm{~mm}$, and (6) distance from supraorbital foramen to the superior orbital fissure 42,32 $\mathrm{mm}$ and 39,39 $\mathrm{mm}$. Conclusion. The most probable safe distances calculated by adopted formula were for the superior orbital fissure 23,39-30,58 mm and for the orbital opening of the optic canal 31,9-38,0 $\mathrm{mm}$ from the bony structures of the orbital entrance depending on the orbital quadrant.

\section{Introduction}

While operating within the orbit surgeon must cope with number of important structures located in a small area, in a nontransparent environment. Position of the soft tissue structures in reference to the easily identifiable bony points is helpful and could prevent serious complications [1-6].
The surgeons should also remember the anatomical variants of the osseous structures of orbit [7]. In our opinion, the published data of the orbital dimensions measured in living patients by multislice computer tomography (MSCT) technique is fragmentary. The majority of published data also concerns other populations than the population of this study [8-10]. The available studies defining safe operating distances 


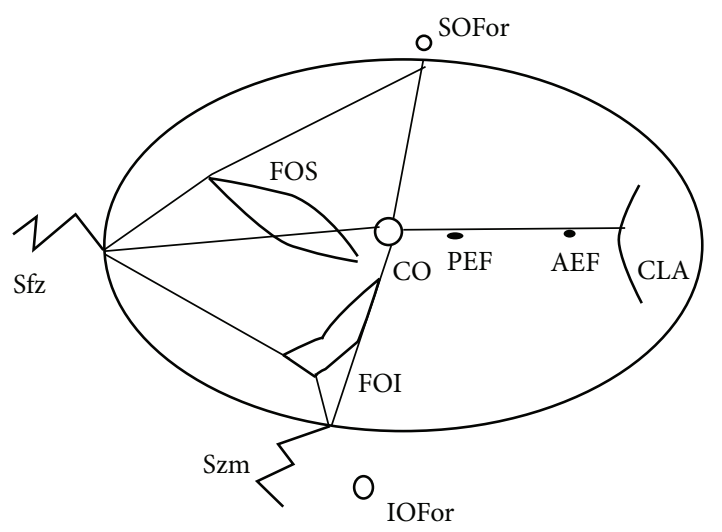

FIGURE 1: The scheme of performed measurements. CLA: lacrimal anterior crest, CO: optic canal, FOS: fissure orbital superior, FOI: fissure orbital inferior, AEF: ethmoidal foramen anterior, PEF: ethmoidal foramen posterior, Sfz: frontozygomatic suture, Szm: zygomaticomaxillar suture, IoFor: infraorbital foramen, and SoFor: supraorbital foramen.

within orbit were made in cadavers [8-18]. Our technique of measurements relaying on MSCT could be used in real life, in preoperative assessment as standard and valuable tool for the surgeon.

The purpose of this study was to determine the minimal safe distances useful for clinical requirements.

\section{Material and Methods}

The study group was constituted by MSCT scans of both orbits of 50 adult Caucasian patients (26 males and 24 females, mean age 56). All the patients were diagnosed in 2nd Department of Clinical Radiology, Warsaw Medical University, Poland, during period from February 2008 to August 2013. The material of the study was collected retrospectively; therefore permission of ethics committee was not needed. The indications for all the examinations were various, nontraumatic pathologies not involving orbital structures. Patients with osseous wall pathologies of the orbit (i.e., traumatic or neoplastic) were excluded from the study group. CT examinations were made in GE Lightspeed 16 Pro scanner with slice thickness of $0.625 \mathrm{~mm}$ and sharp kernel reconstruction. The measurements were made in GE Advantage Windows 4.3 workstation with three-dimensional options. The points of measuring line were inserted in axial scans in appropriate bony structures and then on 3D image the total length between line inserts was noted. This method of placing line inserts in $2 \mathrm{D}$ image and noting the $3 \mathrm{D}$ distance between them was used because of imperfection of solely $3 \mathrm{D}$ measurements. Placing the inserts of the measuring line in high resolution $0,625 \mathrm{~mm} 2 \mathrm{D}$ axial images allowed minimizing calculation error of the $3 \mathrm{D}$ spatial reconstruction.

The following parameters were measured (Figure 1):

(A) on the lateral orbital wall: the distance between intersection of the frontozygomatic suture (FZS) on lateral orbital edge and entrance of optic canal (OC), superior orbital fissure (SOF), and inferior orbital fissure (IOF) (Figure 2);
(B) on the superior wall: the distance between supraorbital notch or foramen and entrance of optic canal, superior orbital fissure, and meningoorbital foramen (Hyrtl canal) (Figure 3);

(C) on the medial orbital wall: the distance between anterior lacrimal crest (ALC) and entrance of optic canal and anterior and posterior ethmoidal foramina (AEF and $\mathrm{PEF}$ ) (Figure 4);

(D) on the inferior orbital wall: the distances between zygomaticomaxillary suture (ZMS) and optic canal and anterior edge of the inferior orbital fissure (Figure 5).

The additional measurement was made on the lateral wall: the distance between intersection of the frontozygomatic suture on lateral orbital edge and meningo-orbital foramen (Hyrtl canal), if this structure was present (Figure 6).

Statistical analysis was performed by STATISTICA v. 8. The value of $p \leq 0.05$ was accepted as statistically important. In certain possible cases double sided critical field was chosen.

The data analysis could be divided into two groups: descriptive (divided by sex and side of the skull) and linear (measurements) variations. The following parameters were measured for linear variations: number, mean asymmetry, standard deviation, median deviation, minimal value, maximal value, kurtosis, and skewness coefficient.

The analysis of mean values was based on parametric Student's $t$-test or Cochran-Cox depending on results of $F$ test in descriptive variation based on sex (analyzing if equal variations parameters in both groups were applied).

Student's $t$-test was applied in descriptive variation based on the skull side (two values in the same patient).

The safe distance values for studied orbits were calculated by subtracting three standard deviation values from the arithmetical average $(X=A V G-3 S T D)$. Safe distance value calculated based on the presented method can cause complication risk of $0,135 \%$. Statistically this is one case per 740 surgical procedures.

\section{Results}

The variation range of the measured parameters according to the gender and skull side/head side is presented in Table 1.

The results of measurements in superior quadrant of the orbit were as follows:

(i) from the optic canal to the supraorbital foramen: mean $46,49 \mathrm{~mm}( \pm 3,20)$ and $43,29( \pm 2,33)$ in men and women, respectively,

(ii) distance from the supraorbital foramen to the superior orbital fissure $42,32 \mathrm{~mm}( \pm 3,92)$ and $39,39 \mathrm{~mm}$ $( \pm 3,21)$ in men and women, respectively.

The results of measurements in inferior quadrant of orbit are as follows: distance from the optic canal to the maxillozygomatic suture at the inferior margin of the orbit mean $45,24 \mathrm{~mm}( \pm 2,91)$ and $42,80 \mathrm{~mm}( \pm 2,41)$ in men and women, respectively. 

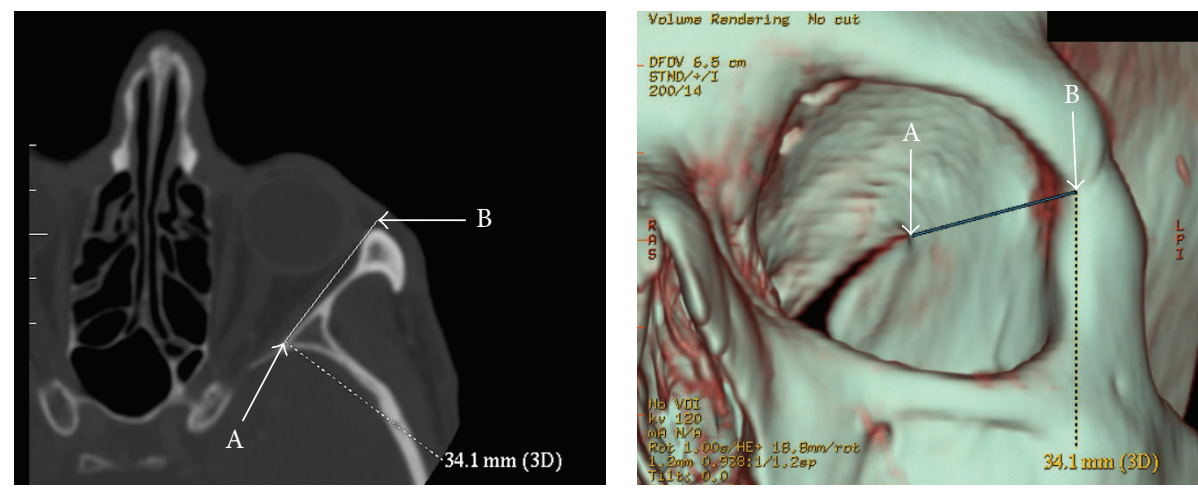

FIGURE 2: The measurements on CT scans (2D and 3D) of the lateral orbital wall structures: (A) superior orbital fissure; (B) frontozygomatic suture. On 2D images the insertions of measure line points were positioned and final measurement was taken from 3D scan.
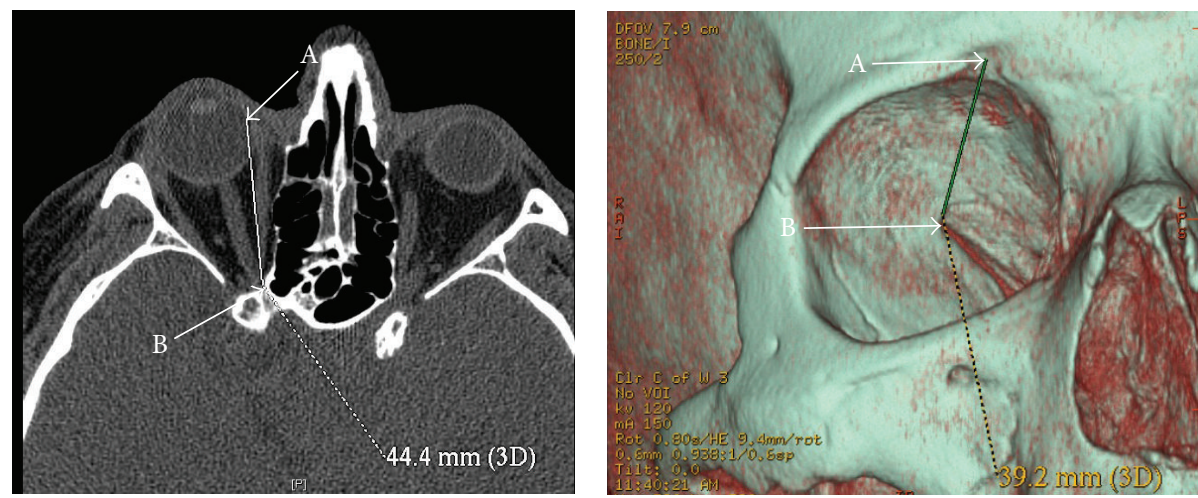

FiguRE 3: The measurements on CT scans of structures of the superior orbital wall. (A) Supraorbital foramen; (B) optic canal.
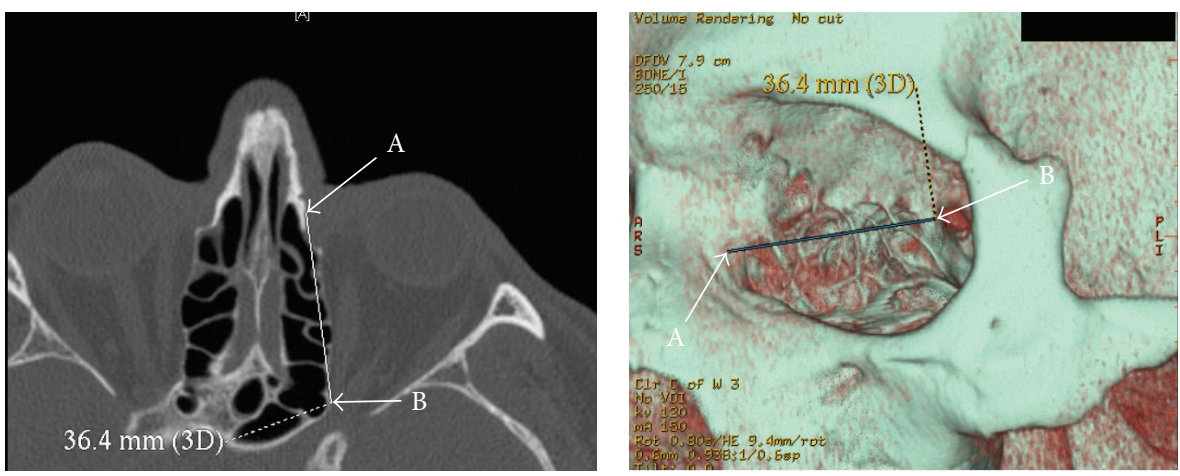

FIGURE 4: The measurements on CT scans of the structures of the medial orbital wall. (A) Anterior lacrimal crest; (B) optic canal. follows:

The results of measurements in lateral quadrant are as

(i) distance from the optic canal to the frontozygomatic suture $46,15 \mathrm{~mm}( \pm 2,70)$ and $43,58 \mathrm{~mm}( \pm 2,05)$ in men and women, respectively,

(ii) distance from the superior orbital fissure to the frontozygomatic suture $34,06 \mathrm{~mm}( \pm 3,32)$ and $32,62 \mathrm{~mm}$ $( \pm 2,99)$ in men and women, respectively.

The results of measurements in medial quadrant of orbit consisted of the distance from the optic canal to the anterior lacrimal crest, which had 40,40 $\mathrm{mm}( \pm 2,76)$ and $38,39 \mathrm{~mm}$ $( \pm 1,85)$ in men and women, respectively.

The analysis of data from tables showed that there were statistically significant differences between dimensions measured on CT scans depending on gender, greater value in males compared to females $(p<0.05)$.

There were some statistically significant differences between right and left sides in the studied cases.

The distance between the OC and the ALC was bigger on the right side in both females $(p=0,0011)$ and males $(p=0,0346)$. The distance between IOF and FZS was bigger 
TABLE 1: Variation range of the individual orbit parameters on CT (given in mm). Bold: mean arithmetic, in parenthesis: standard deviation, and underneath: min and max values.

\begin{tabular}{|c|c|c|c|c|}
\hline & Orbital dimensions & & $\begin{array}{c}\text { Male }(n=52) \\
\mathrm{R}+\mathrm{L}\end{array}$ & $\begin{array}{c}\text { Female }(n=48) \\
\mathrm{R}+\mathrm{L}\end{array}$ \\
\hline \multirow{2}{*}{ Roof of the orbit } & \multirow{2}{*}{ Supraorbital foramen } & Optic canal & $\begin{array}{c}\mathbf{4 6 , 4 9}(3,20) \\
39,6-52,8\end{array}$ & $\begin{array}{c}\mathbf{4 3 , 2 9}(2,33) \\
38,4-48,3\end{array}$ \\
\hline & & Superior orbital fissure & $\begin{array}{c}42,32(3,92) \\
34,6-50,1\end{array}$ & $\begin{array}{c}39,39(3,21) \\
32,5-48,0\end{array}$ \\
\hline \multirow{3}{*}{ Lateral wall } & \multirow{3}{*}{ Frontozygomatic suture } & Optic canal & $\begin{array}{c}\mathbf{4 6 , 1 5}(2,70) \\
41,0-51,6\end{array}$ & $\begin{array}{c}\mathbf{4 3 , 5 8}(2,05) \\
39,0-47,0\end{array}$ \\
\hline & & Superior orbital fissure & $\begin{array}{c}34,06(3,32) \\
24,4-41,3\end{array}$ & $\begin{array}{c}32,62(2,99) \\
26,4-39,6\end{array}$ \\
\hline & & Interior orbital fissure & $\begin{array}{c}24,62(3,01) \\
15,0-30,4\end{array}$ & $\begin{array}{c}23,46(2,69) \\
17,0-29,7\end{array}$ \\
\hline \multirow{3}{*}{ Medial wall } & \multirow{3}{*}{ Anterior lacrimal crest } & Optic canal & $\begin{array}{c}\mathbf{4 0 , 4 0}(2,76) \\
34,3-48,0\end{array}$ & $\begin{array}{c}38,39(1,85) \\
34,8-42,8\end{array}$ \\
\hline & & Anterior ethmoidal foramen & $\begin{array}{c}\mathbf{2 1 , 2 8}(2,76) \\
16,0-28,9\end{array}$ & $\begin{array}{c}\mathbf{2 0 , 5 5}(2,29) \\
15,0-25,0\end{array}$ \\
\hline & & Posterior ethmoidal foramen & $\begin{array}{c}33,06(3,52) \\
24,8-40,0\end{array}$ & $\begin{array}{c}31,8(3,43) \\
20,4-36,8\end{array}$ \\
\hline \multirow{2}{*}{ Floor of orbit } & \multirow{2}{*}{ Zygomaticomaxillary suture } & Optic canal & $\begin{array}{c}45,24(2,91) \\
39,3-52,5\end{array}$ & $\begin{array}{c}\mathbf{4 2 , 8}(2,41) \\
37,2-48,7\end{array}$ \\
\hline & & Inferior orbital fissure & $\begin{array}{c}23,33(2,69) \\
16,0-27,7\end{array}$ & $\begin{array}{c}20,85(2,89) \\
15,7-28,0\end{array}$ \\
\hline
\end{tabular}
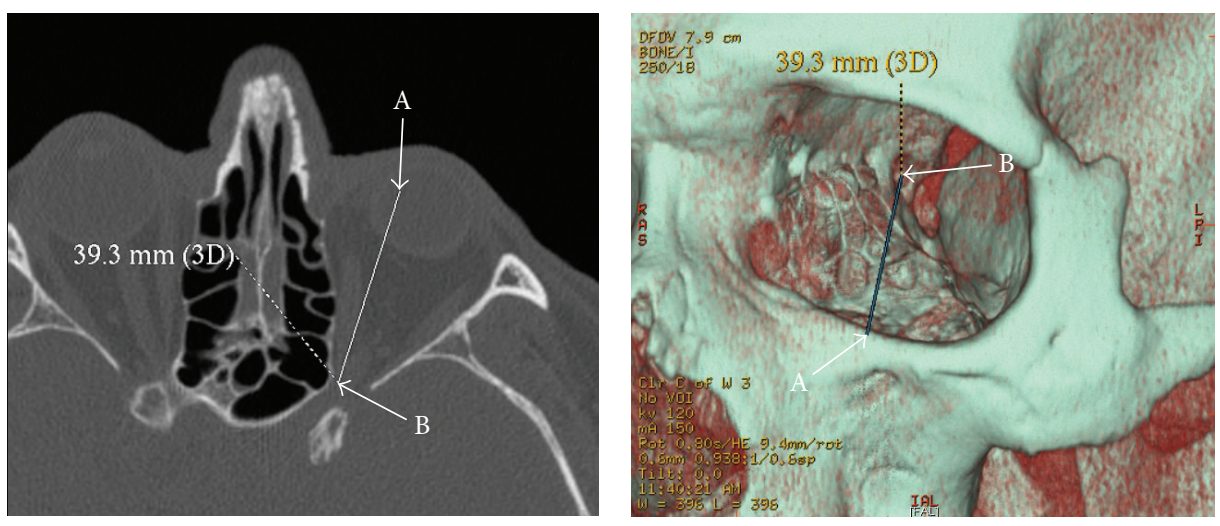

FIGURE 5: The measurements on CT scans: structures of the inferior orbital wall. (A) Zygomaticomaxillary suture; (B) optic canal.
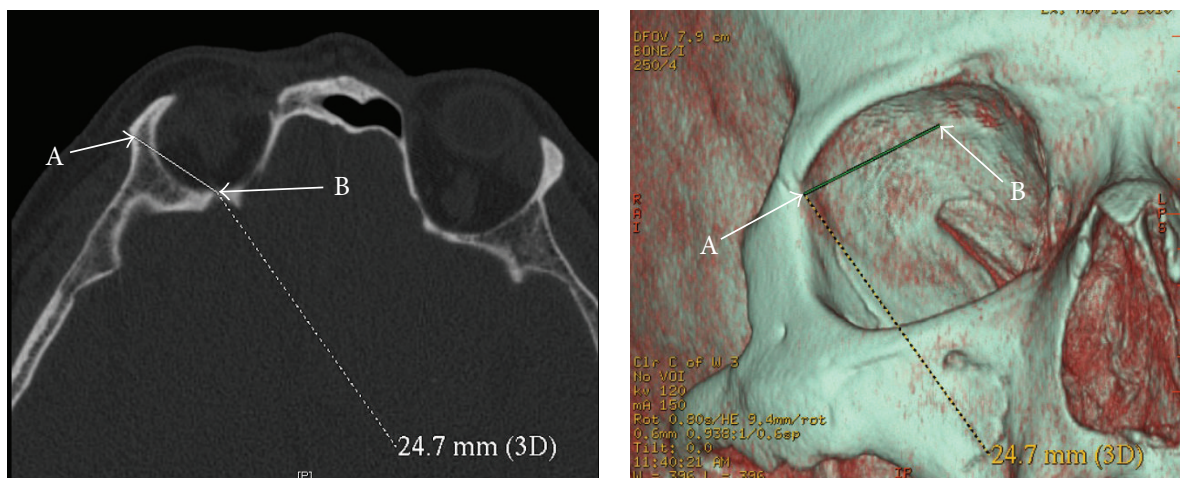

FIgURE 6: The measurements on CT scans: Hyrtl's canal location considering frontozygomatic suture. (A) Frontozygomatic suture; (B) meningoorbital foramen (Hyrtl's canal). 
TABLE 2: The most probable safe distances values in the CT (given in $\mathrm{mm})$.

\begin{tabular}{|c|c|c|c|c|}
\hline \multirow[b]{2}{*}{ Distance } & \multicolumn{2}{|c|}{ M } & \multicolumn{2}{|c|}{ F } \\
\hline & $\begin{array}{c}\mathrm{R} \\
(N=26)\end{array}$ & $\begin{array}{c}\mathrm{L} \\
(N=26)\end{array}$ & $\begin{array}{c}\mathrm{R} \\
(N=24)\end{array}$ & $\begin{array}{c}\mathrm{L} \\
(N=24)\end{array}$ \\
\hline \multicolumn{5}{|l|}{ ALC } \\
\hline OC & 32,34 & 31,90 & 33,60 & 32,27 \\
\hline $\mathrm{AEF}$ & 12,74 & 13,15 & 14,41 & 12,95 \\
\hline PEF & 21,69 & 23,16 & 20,92 & 21,97 \\
\hline \multicolumn{5}{|l|}{ FZS } \\
\hline OC & 37,91 & 38,02 & 37,79 & 36,94 \\
\hline SOF & 23,64 & 24,49 & 23,73 & 23,39 \\
\hline IOF & 15,85 & 15,22 & 16,60 & 14,35 \\
\hline \multicolumn{5}{|c|}{$\begin{array}{l}\text { Zygomaticomaxillary } \\
\text { suture }\end{array}$} \\
\hline OC & 36,83 & 36,10 & 34,65 & 36,46 \\
\hline IOF & 16,15 & 14,76 & 13,96 & 11,74 \\
\hline \multicolumn{5}{|c|}{$\begin{array}{l}\text { Supraorbital } \\
\text { foramen/notch }\end{array}$} \\
\hline OC & 36,32 & 37,27 & 36,24 & 36,20 \\
\hline SOF & 30,49 & 30,58 & 30,30 & 29,22 \\
\hline
\end{tabular}

on the right side in females $(p=0,0336)$. Also the distance between IOF and ZMS was bigger on the right side both in females $(p=0,0008)$ and in males $(p=0,0491)$ (Table 2$)$.

There were no other statistically significant differences in measured values between sides in the study group.

The location of Hyrtl canal was noted in 5 cases between all 100 orbits (5\%). The distance between meningo-orbital foramen and FZS was 24,7-32,3 mm and between meningoorbital foramen and supraorbital foramen was $25,1-36,4 \mathrm{~mm}$ (Table 4).

The safe distances were calculated by inserting average values and standard deviations to the formula $X=\mathrm{AVG}-$ 3 STD. The results of these calculations are presented in Tables 2 and 3. The superior orbital fissure and orbital opening of the optic canal are located no shallower than $23,6 \mathrm{~mm}$ and $38,0 \mathrm{~mm}$ from the bony structures of the orbital entrance, respectively, and these values constitute the safe distances for operating purposes.

The safe distances for superior quadrant of the orbit were equal: from $\mathrm{OC}$ to supraorbital foramen the distance was $36,9 \mathrm{~mm}$ in men and $36,3 \mathrm{~mm}$ in women and from supraorbital foramen to SOF the distance was $30,5 \mathrm{~mm}$ in men and $29,8 \mathrm{~mm}$ in women.

The safe distances for inferior quadrant of orbit are as follows: from OC to ZMS at the inferior margin of the orbit the distance was 34,65-36,83 $\mathrm{mm}$ depending on sex and side.

The safe distances for lateral quadrant are as follows: distance from OC to FZS was 38,0 mm in men and $37,43 \mathrm{~mm}$ in women and distance from SOF to FZS was $24,1 \mathrm{~mm}$ in men and $23,7 \mathrm{~mm}$ in women.

The safe distances for medial quadrant of orbit are as follows: distance from the OC to ALC was $31,9-33,6 \mathrm{~mm}$ depending on sex and side.

\section{Discussion}

Modern technologies, such as surgical navigation systems, used in the orbit surgery make surgical procedures more safe and they are increasing accuracy of reconstruction [19]. Beside that convenient surgery support, operator needs to be familiar with minimal distances from the orbit structures to the optic canal.

There are only few papers in the available literature, which could be referred to the results obtained in this study. Simonton et al. [20] determined safe distances for lateral orbitotomy, but their measurements were closely related to the cranial cavity. In our study we have described distinctive topographical points, which are easy to find in the orbit entrance plane. The most probable safe minimal distances to the optic canal were established from these points (Table 3) (Figure 1).

4.1. Medial Wall. These distances are especially important in surgical procedures such as ethmoid vessel ligation, exploration of the medial wall fractures, the anterior skull base reconstruction, tumour resection, ethmoid sinus exenteration, orbital decompression, transethmoidal sphenoidotomies, closure of cerebrospinal fluid leakage, and transethmoidal and sphenoidal hypophysectomy [17, 18, 21-25]. The reference point in the medial quadrant is the anterior lacrimal crest which is located, according to various authors, 29$53 \mathrm{~mm}$ from the entrance of the optic canal $[10,12,14,15$, 18]. In our material this distance was $40,4 \mathrm{~mm}$ for men and $38,39 \mathrm{~mm}$ for women (Table 1 ). There were statistically important differences in OC-ALC distance between right and left sides both in women $(p=0,0011)$ and in men $(p=$ $0,0346)$. The greater values were measured on the right side. This observation confirms the data published by Kadanoff and Jordanov [26]. In this paper wider orbits were observed on the right side in $63 \%$ of cases and on the left side in $15,4 \%$. The mean values of OC-ALC distance in other populations were bigger than in our material (Table 5): in Indian $42 \mathrm{~mm}$ [18], in American 43,29 mm [15], in Korean 40,5 mm [9], in male Turkish 41,7 mm [14], in British Caucasian 43,77 mm [11], in Thai 42,2 $\mathrm{mm}$ [13], significantly bigger in Egyptians, men 47,25 $\mathrm{mm}$ and women 46,21 $\mathrm{mm}$ [8] $(p<0.05)$, and in Chinese, men 46,43 $\mathrm{mm}$ and women $44,41 \mathrm{~mm}(p<0.05)$ [10] (Table 5).

The anterior and posterior ethmoidal foramina are important structures of medial orbital wall. They have relatively variable position to the ALC and frontoethmoidal suture and also vary in number with accessory foramina $[11,17,18,24,27]$. Single accessory ethmoidal foramina were detected in $38 \%$ and double foramina in $2,4 \%$ by Takahashi et al. [24]. The accessory ethmoidal foramina were defined in the above-mentioned paper as located between anterior and posterior ethmoidal foramina. When only one was present, it was named middle ethmoidal foramen; when two were present, the one located closer to the posterior ethmoidal foramen was named deep middle ethmoidal foramen [24]. 


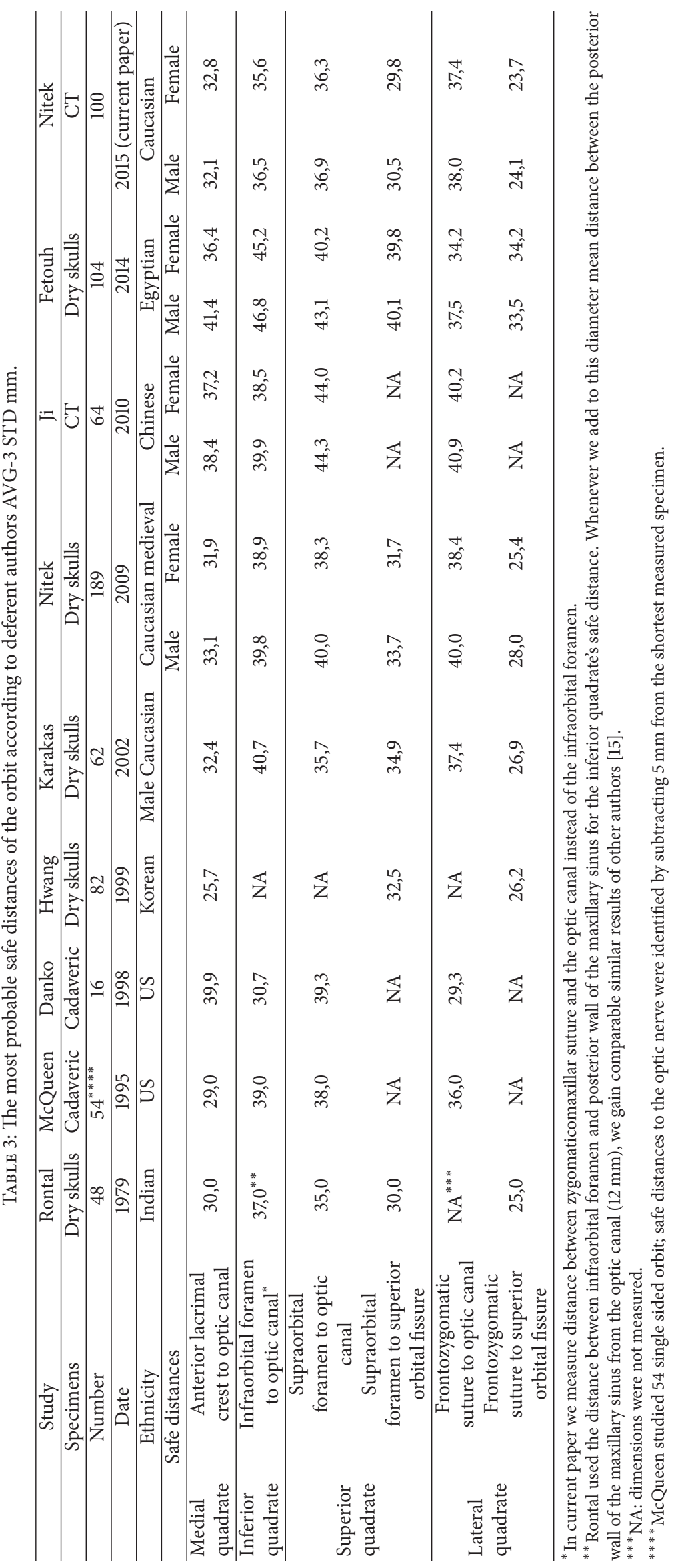


TABLE 4: Distances of bony structures not permanently present in the orbit [mm].

\begin{tabular}{|c|c|c|c|}
\hline Measured distance & $\mathrm{R}$ & $\mathrm{L}$ & $\mathrm{R}+\mathrm{L}$ \\
\hline Supraorbital foramen-Hyrtl canal & $\begin{array}{c}N=3 \\
\text { Mean 30,5 } \\
25,1-36,4\end{array}$ & $\begin{array}{c}N=2 \\
\text { Mean 30,55 } \\
25,8-35,3\end{array}$ & $\begin{array}{c}N=5 \\
\text { Mean 30,52 } \\
25,1-36,4\end{array}$ \\
\hline Frontozygomatic suture-Hyrtl canal & $\begin{array}{c}N=3 \\
\text { Mean 27,33 } \\
24,7-32,3 \\
\end{array}$ & $\begin{array}{c}N=2 \\
\text { Mean 26,1 } \\
26,0-26,2\end{array}$ & $\begin{array}{c}N=5 \\
\text { Mean 26,84 } \\
24,7-32,3 \\
\end{array}$ \\
\hline Anterior lacrimal crest-accessory posterior ethmoidal foramen & $\begin{array}{c}N=4 \\
\text { Mean 34,85 } \\
33,9-36,5\end{array}$ & $\begin{array}{c}N=6 \\
\text { Mean 33,08 } \\
28,3-37,6\end{array}$ & $\begin{array}{c}N=10 \\
\text { Mean 33,79 } \\
28,3-37,6\end{array}$ \\
\hline
\end{tabular}

Piagkou classified the ethmoidal foramina pattern in the medial wall as types I-IV according to their number:

(1) type I: single ethmoidal foramen (usually isolated AEF) was observed in 1,6\% [17] and in 0,8\% [28],

(2) type II: double EF (the most common, single AEF and PEF, each) was observed in 61\% [17] and in 73,7\% [28],

(3) type III: triple EF was observed in $28,5 \%$ [17] and in $24,4 \%[28]$,

(4) type IV: multiple EF was observed in $8,8 \%$ [17] and quadruple EF in $1,1 \%$ [28].

In our material accessory posterior ethmoidal foramen was observed in $10 \%$ of the cases. According to other authors incidence of more than one PEF is above $25 \%$ [18]. In other papers [28] EFs were identified as single in $0.8 \%$, double in $73.7 \%$, triple $24,4 \%$, and quadruple in $1.1 \%$ of the specimens. The mean distances between ALC and AEF, ALC and PEF, and ALC and MEF were $27.7 \mathrm{~mm}, 10.6 \mathrm{~mm}$, and $12.95 \mathrm{~mm}$, respectively. The distances from ALC-AEF, AEF$\mathrm{PEF}$, and PEF-OC were $27.7 \mathrm{~mm} \pm 2.8,10.6 \mathrm{~mm} \pm 3.3$, and $5.4 \mathrm{~mm} \pm 1 \mathrm{~mm}$. The ethmoidal foramina are located in the frontoethmoidal suture line in $68 \%$ of cases and above this line in about $20 \%$ [24] or according to other authors in $32 \%$ of cases 1-4 mm above the suture [27]. The key role in surgery of medial orbital wall is reserved for the distance between PEF and OC, which according to Rontal is no less than $3 \mathrm{~mm}$ [18]. But other authors observed this distance between 4,3 $\mathrm{mm}$ [17] and 7,25 $\mathrm{mm}$ [29]. Other authors gave arithmetic average of this value (Table 5) $[11,13,14,24]$. Abed distinguished first PEF (mean 11,63 mm from OC) and last PEF (mean 7,25 mm from OC) [11]. In our material mean distance from $P E F$ to OC was $7 \mathrm{~mm}$ (first PEF), like in Harrison $7 \mathrm{~mm}$ for the first PEF and 5,65 $\mathrm{mm}$ for the last PEF [30]. Harrison observed that in $30 \%$ there are multiple EFs and in those cases this distance may be only $2 \mathrm{~mm}$ short [30]. This situation may increase risk of optic nerve injury during coagulation of the posterior ethmoidal artery.

The most probable safe distance for medial wall of orbit according to our measurements is $31,9-33,6 \mathrm{~mm}$ for ALCCO, 12,7-14,4 mm for ALC-AEF, and 20,9-23,16 mm for ALCPEF depending on sex and side. The results obtained by other authors are similar and are in range $29-41,4 \mathrm{~mm}$ for ALC-CO $[8-10,12,14,15]$.
4.2. Superior Wall. The most frequent of surgical procedures of superior orbital wallare frontal ethmoidectomy, frontal sinus trephine, frontal sinus obliteration, orbital decompression, exploration for fractures, lacrimal gland, or other tumours' excision and orbital exenteration [18, 22]. The incision must be made just below the eyebrow if the supraorbital nerve and the elevator muscle of the upper lid are to remain intact $[18,30]$. The supraorbital notch or foramen is usually found in parasagittal line connecting the mental foramen with the infraorbital foramen [18] and about $5 \mathrm{~mm}$ from the orbital margin [30]. Mean values of distance from the supraorbital foramen/notch to the optic canal are usually between $40 \mathrm{~mm}$ and $52,93 \mathrm{~mm}$ according to other authors $[8,10,12-15,18]$. In our material this distance was $46,49 \pm 3,2 \mathrm{~mm}$ for men and 43,2 $\pm 2,33 \mathrm{~mm}$ for women. The superior orbital fissure is usually located $35-52 \mathrm{~mm}$ from the supraorbital foramen/notch $[8,10,12-15,18]$. In our material this distance was $42,3 \pm 3,92 \mathrm{~mm}$ for men and 39,39 $\pm 3,21 \mathrm{~mm}$ for women. Mean values of supraorbital foramen to optic canal in our material were comparable to other populations $[12-15,18]$ but were statistically significantly lower than in Chinese population $(52,9 \mathrm{~mm}$ and $50,89 \mathrm{~mm}$ for men and women, resp.) [10], Kenyan population (53,25 mm and 51,93 $\mathrm{mm}$ for men and women, resp.) [16], and Egyptian population $(49,64 \mathrm{~mm}$ and $48,16 \mathrm{~mm}$ for men and women, resp.) [8]. The most probable safe distance for orbital roof concluding from our study was $30 \mathrm{~mm}$ for superior orbital fissure and $35 \mathrm{~mm}$ for optic canal. Rontal also provided similar safe distance: $30 \mathrm{~mm}$ for orbital roof [18]. The results of other authors are similar and are between $35-43,7 \mathrm{~mm}$ for superior orbital foramen, OC, and 31,9-40,1 $\mathrm{mm}$ for superior orbital foramen, SOF [8-10, 12, 14, 15].

4.3. Lateral Wall. The knowledge of lateral orbital wall anatomy is crucial for all the surgical procedures, like explorations of orbital fractures, lateral orbitotomy during tumour excisions, orbital decompression, and excisions of the lacrimal gland [18, 22, 25].

The mean distance between frontozygomatic suture and the optic canal was measured between 40 and $53 \mathrm{~mm}[10,12$, $14,15,18]$. In our material this distance was $46,15 \pm 2,70 \mathrm{~mm}$ for men and 43,58 $\pm 2,05 \mathrm{~mm}$ for women.

The mean distance between FZS and SOF was found between $34,5 \mathrm{~mm}$ and 39,94 $\mathrm{mm}$ [8, 10, 12, 14-16, 18]. In our material this distance was $34,06 \pm 3,32 \mathrm{~mm}$ for men and 32,62 


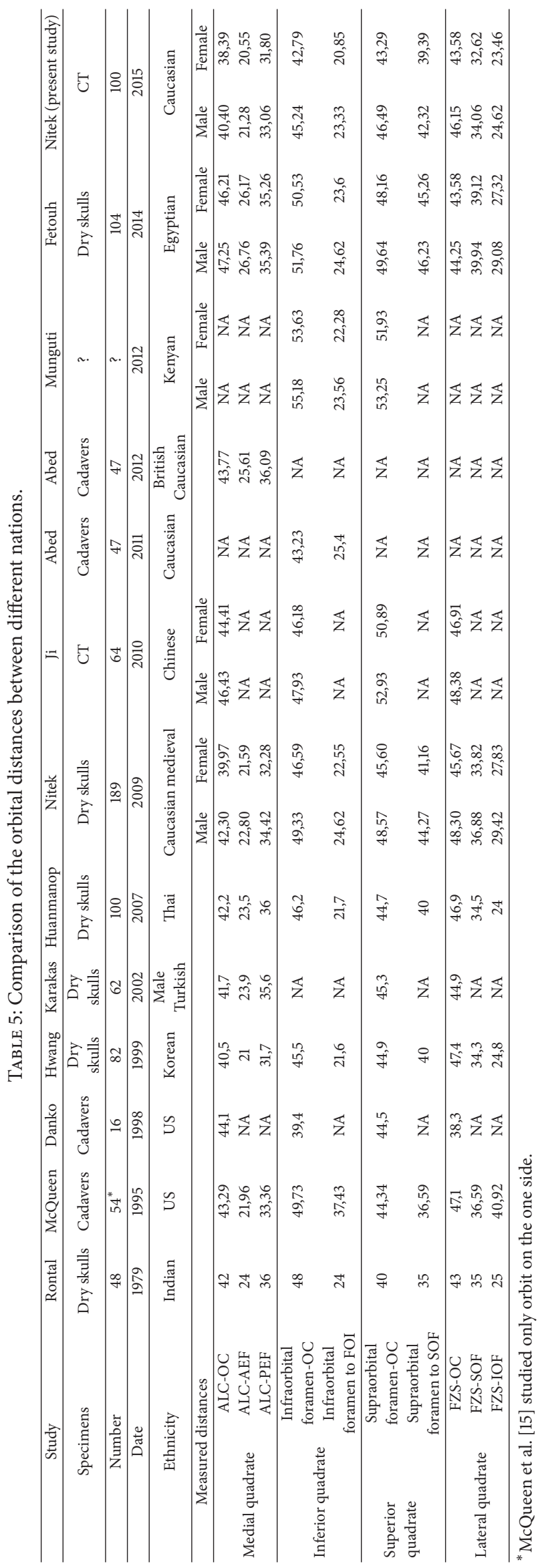


$\pm 2,99 \mathrm{~mm}$ for women. The mean distances for FZS-OC and FZS- SOF for other populations are similar to our results (Table 5) $[12,14,15,18]$ except Chinese [10] and Egyptian [8] populations. The safe distance for FZS-OC calculated by our model is $38,0 \mathrm{~mm}$ in men and $37,43 \mathrm{~mm}$ in women; the most probable safe distance from SOF to FZS is $24,1 \mathrm{~mm}$ in men and $23,6 \mathrm{~mm}$ in women.

The results of calculations of safe distances by other authors are similar to our results and are in the range 29,3$40,5 \mathrm{~mm}$ for FZS-OC and 25-34,2 $\mathrm{mm}$ for FZS-SOF [8-10, 12 , $14,15]$.

4.4. Inferior Wall. The knowledge of inferior wall anatomy is important for several procedures, that is, maxillectomy, explorations of fractures, or tumour resection [18, 22]. The posterior wall of the maxilla lies as close as $26 \mathrm{~mm}$ from the infraorbital foramen [18]. The optic canal lies usually about $12 \mathrm{~mm}$ beyond this point [18]. The measurements of distances between zygomaticomaxillary suture, the optic canal, and anterior edge of the inferior orbital fissure are in our opinion better than dimensions from infraorbital foramen because the zygomaticomaxillary suture is easier to be palpated by the surgeon. The mean distance of the optic canal to the infraorbital foramen is reported between 39,4 and $55,18 \mathrm{~mm}$ $[8-10,12,13,16,18,31]$. In our material this distance was $45,24 \mathrm{~mm}$ for men and $42,79 \mathrm{~mm}$ for women. This distance was statistically significantly greater in Kenyan population $55,18 \mathrm{~mm}$ for men and 53,63 $\mathrm{mm}$ for women [16]. The mean values of distance inferior orbital fissure from the infraorbital foramen are reported in range $21,7-37,43 \mathrm{~mm}[5,8,9,13,15$, $16,18]$. In our material this distance was $23,3 \mathrm{~mm}$ for men and $20,8 \mathrm{~mm}$ for women.

There were clear differences in distances concerning SOF on the right and left sides due to different shapes of SOF [8]. The variation range determined during our study covers the majority of the average values provided in the literature. The presence of meningo-orbital foramen (Hyrtl canal) in 5\% of cases is worth mentioning. According to other authors this variant is found in $6-55 \%$ of population $[7,15,18,32,33]$. It is a potential source of hemorrhage during deep lateral orbital dissection, because it functions as an anastomosis between the lacrimal artery and the middle meningeal artery $[7,18,31,32]$. The distance between meningo-orbital foramen and FZS was found in range of $25-39 \mathrm{~mm}[15,18,31,32]$. In our material this distance was in range of $24,7-32,3 \mathrm{~mm}$ (Table 4). The distance between meningo-orbital foramen and supraorbital foramen was reported in range of $12-37 \mathrm{~mm}$ $[15,18,32,33]$. In our material this distance was $25,1-36,4 \mathrm{~mm}$ (Table 4).

Assessment of the most probable safe distances calculated in this paper is also comparable to the data provided by other authors $[9,14,15,18]$. Only the data on Egyptians published by Fetouh and Mandour [8] and by Danko and Haug [12] show significant difference (Table 3 ). It can be explained by relatively small study group of these papers, consisting of only 8 cases (16 orbits). Beside that Danko and Haug [12] performed their measurements on specimens with preserved soft tissues unlike other authors who used macerated skulls.
McQueen et al. [15] calculated the safe distances by subtracting $5 \mathrm{~mm}$ from the lowest obtained value. In our study the formula $X=\mathrm{AVG}-3$ STD was applied. Despite different criteria used to determine the safe distances and genetic differences of the examined material the results are comparable. We speculate that population differences do not significantly influence the safe distances values in the orbit because they provide a large safety margin and vary between 23,39-30,58 $\mathrm{mm}$ for the superior orbital fissure and 31,90$38,02 \mathrm{~mm}$ for the orbital opening of the optic canal from the bony structures of the orbital entrance depending on the orbital quadrant (Table 2).

\section{Conflict of Interests}

The authors declare that they have no conflict of interests with any organization nor institute.

\section{References}

[1] B. T. Evans and A. A. C. Webb, "Post-traumatic orbital reconstruction: anatomical landmarks and the concept of the deep orbit," British Journal of Oral and Maxillofacial Surgery, vol. 45, no. 3, pp. 183-189, 2007.

[2] L. G. Farkas and J. C. Kolar, "Anthropometric guidelines in cranio-orbital surgery," Clinics in Plastic Surgery, vol. 14, no. 1, pp. 1-16, 1987.

[3] K. J. Kent, G. E. Merwin, and K. E. Rarey, "Margins of safety with transantral orbital decompression," Laryngoscope, vol. 98, no. 8, pp. 815-817, 1988.

[4] Y. Natori and A. L. Rhoton Jr., "Transcranial approach to the orbit: microsurgical anatomy," Journal of Neurosurgery, vol. 81, no. 1, pp. 78-86, 1994.

[5] S. Nitek, J. Wysocki, J. Reymond, and K. Piasecki, "Correlations between selected parameters of the human skull and orbit," Medical Science Monitor, vol. 15, no. 12, pp. BR370-BR377, 2009.

[6] J. Reymond, J. Kwiatkowski, and J. Wysocki, "Clinical anatomy of the superior orbital fissure and the orbital apex," Journal of Cranio-Maxillofacial Surgery, vol. 36, no. 6, pp. 346-353, 2008.

[7] M. Erturk, G. Kayalioglu, F. Govsa, T. Varol, and T. Ozgur, "The cranio-orbital foramen, the groove on the lateral wall of the human orbit, and the orbital branch of the middle meningeal artery," Clinical Anatomy, vol. 18, no. 1, pp. 10-14, 2005.

[8] F. A. Fetouh and D. Mandour, "Morphometric analysis of the orbit in adult Egyptian skulls and its surgical relevance," European Journal of Anatomy, vol. 18, no. 4, pp. 303-315, 2014.

[9] K. Hwang and S. H. Baik, "Surgical anatomy of the orbit of Korean adults," Journal of Craniofacial Surgery, vol. 10, no. 2, pp. 129-134, 1999.

[10] Y. Ji, Z. Qian, Y. Dong, H. Zhou, and X. Fan, "Quantitative morphometry of the orbit in Chinese adults based on a threedimensional reconstruction method," Journal of Anatomy, vol. 217, no. 5, pp. 501-506, 2010.

[11] S. F. Abed, P. Shams, S. Shen, P. J. Adds, and J. M. Uddin, "A cadaveric study of ethmoidal foramina variation and its surgical significance in Caucasians," British Journal of Ophthalmology, vol. 96, no. 1, pp. 118-121, 2012.

[12] I. Danko and R. H. Haug, "An experimental investigation of the safe distance for internal orbital dissection," Journal of Oral and Maxillofacial Surgery, vol. 56, no. 6, pp. 749-752, 1998. 
[13] T. Huanmanop, S. Agthong, and V. Chentanez, "Surgical anatomy of fissures and foramina in the orbits of Thai adults," Journal of the Medical Association of Thailand, vol. 90, no. 11, pp. 2383-2391, 2007.

[14] P. Karakas, M. G. Bozkir, and Ö. Oguz, "Morphometric measurements from various reference points in the orbit of male Caucasians," Surgical and Radiologic Anatomy, vol. 24, no. 6, pp. 358-362, 2002.

[15] C. T. McQueen, D. C. DiRuggiero, J. P. Campbell, and W. W. Shockley, "Orbital osteology: a study of the surgical landmarks," Laryngoscope, vol. 105, no. 8, pp. 783-788, 1995.

[16] J. Munguti, P. Mandela, and F. Butt, "Referencing orbital measures for surgical and cosmetic procedures," Anatomy Journal of Africa, vol. 1, pp. 40-45, 2012.

[17] M. Piagkou, G. Skotsimara, A. Dalaka et al., "Bony landmarks of the medial orbital wall: an anatomical study of ethmoidal foramina," Clinical Anatomy, vol. 27, no. 4, pp. 570-577, 2014.

[18] E. Rontal, M. Rontal, and F. T. Guilford, "Surgical anatomy of the orbit," Annals of Otology, Rhinology and Laryngology, vol. 88, no. 3, pp. 382-386, 1979.

[19] M. Rana, C. H. Chui, M. Wagner, R. Zimmerer, M. Rana, and N. C. Gellrich, "Increasing the accuracy of orbital reconstruction with selective laser-melted patient-specific implants combined with intraoperative navigation," Journal of Oral and Maxillofacial Surgery, vol. 73, no. 6, pp. 1113-1118, 2015.

[20] J. T. Simonton, P. F. Garber, and N. Ahl, "Margins of safety in lateral orbitotomy," Archives of Ophthalmology, vol. 95, no. 7, pp. 1229-1231, 1977.

[21] S. R. Aziz, J. M. Marchena, and A. Puran, "Anatomic characteristics of the infraorbital foramen: a cadaver study," Journal of Oral and Maxillofacial Surgery, vol. 58, no. 9, pp. 992-996, 2000.

[22] K. P. Cockerham, G. K. Bejjani, J. S. Kennerdell, and J. C. Maroon, "Surgery for orbital tumors. Part II: transorbital approaches," Neurosurgical Focus, vol. 10, no. 5, article E3, 2001.

[23] H. Kakizaki, T. Nakano, K. Asamoto, and M. Iwaki, "Posterior border of the deep lateral orbital wall-appearance, width, and distance from the orbital rim," Ophthalmic Plastic and Reconstructive Surgery, vol. 24, no. 4, pp. 262-265, 2008.

[24] Y. Takahashi, H. Kakizaki, T. Nakano, K. Asamoto, A. Ichinose, and M. Iwaki, "An anatomical study of the positional relationship between the ethmoidal foramina and the frontoethmoidal suture," Ophthalmic Plastic and Reconstructive Surgery, vol. 27, no. 6, pp. 457-459, 2011.

[25] Y. Takahashi, H. Miyazaki, A. Ichinose, T. Nakano, K. Asamoto, and H. Kakizaki, "Anatomy of deep lateral and medial orbital walls: implications in orbital decompression surgery," Orbit, vol. 32, no. 6, pp. 409-412, 2013.

[26] D. Kadanoff and J. Jordanov, "Asymmetry of form and size of the human aditus orbitae," Verhandlungen der Anatomischen Gesellschaft, vol. 71, part 2, pp. 1283-1288, 1977.

[27] J. A. Kirchner, E. Yanagisawa, and E. S. Crelin Jr., "Surgical anatomy of the ethmoidal arteries," Archives of Otolaryngology, vol. 74, pp. 382-386, 1961.

[28] S. Celik, M. A. Ozer, Z. Kazak, and F. Govsa, "Computer-assisted analysis of anatomical relationships of the ethmoidal foramina and optic canal along the medial orbital wall," European Archives of Oto-Rhino-Laryngology, vol. 272, no. 11, pp. 3483-3490, 2014.

[29] A. C. Cheng, P. W. Lucas, H. K. Yuen, D. S. Lam, and K. F. So, "Surgical anatomy of the Chinese orbit," Ophthalmic Plastic \& Reconstructive Surgery, vol. 24, no. 2, pp. 136-141, 2008.
[30] D. F. Harrison, “The ENT surgeon looks at the orbit," The Journal of Laryngology \& Otology, no. 3, pp. 1-43, 1980.

[31] S. F. Abed, P. N. Shams, S. Shen, P. J. Adds, and J. M. Uddin, "Morphometric and geometric anatomy of the caucasian orbital floor," Orbit, vol. 30, no. 5, pp. 214-220, 2011.

[32] S. F. Abed, P. Shams, S. Shen, P. J. Adds, J. M. Uddin, and M. Manisali, "A cadaveric study of the cranio-orbital foramen and its significance in orbital surgery," Plastic and Reconstructive Surgery, vol. 129, no. 2, pp. 307e-31le, 2012.

[33] S. Celik, Z. Kazak, M. A. Ozer, and F. Govsa, "Navigational area of the cranio-orbital foramen and its significance in orbital surgery," Surgical and Radiologic Anatomy, vol. 36, no. 10, pp. 981-988, 2014. 

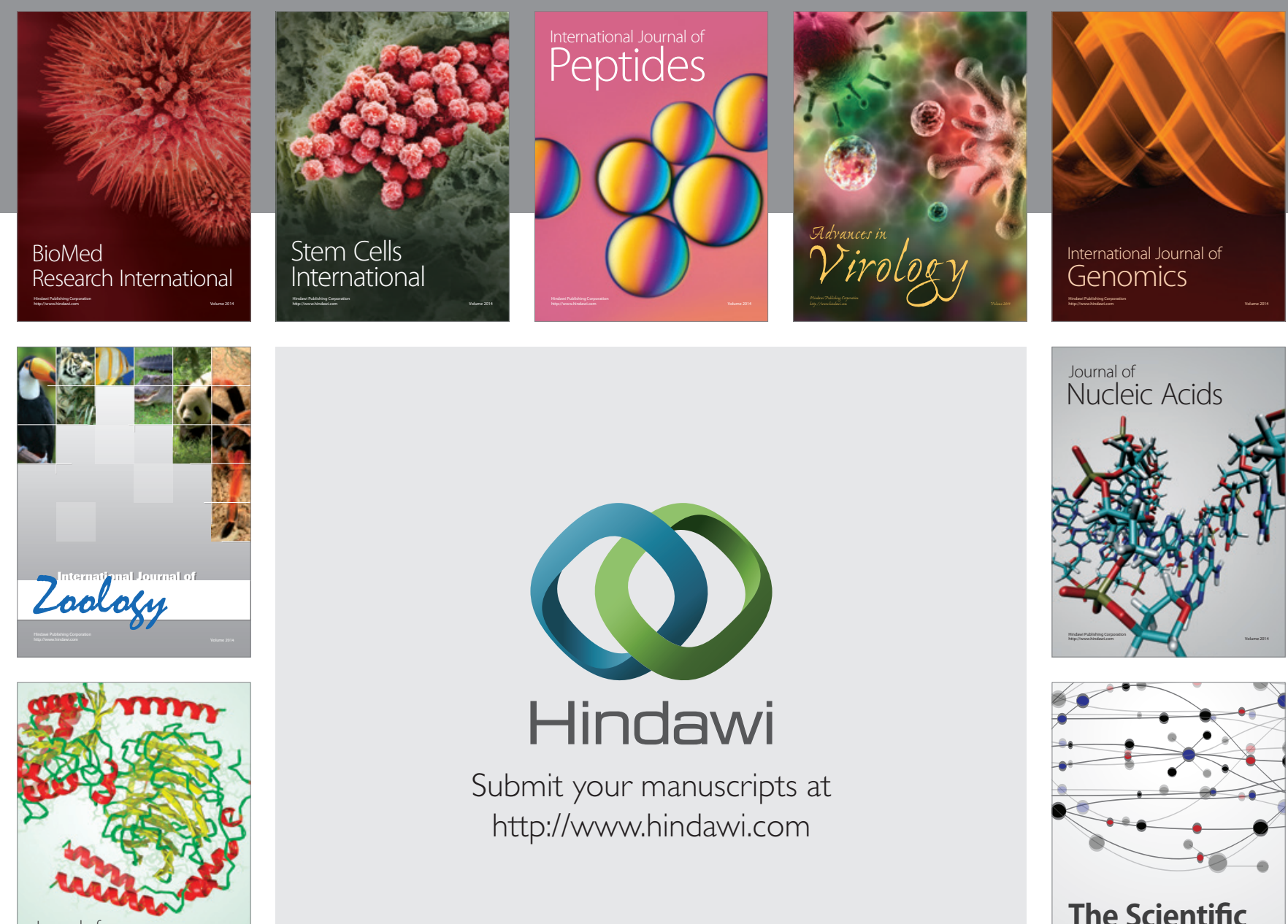

Submit your manuscripts at

http://www.hindawi.com

Journal of
Signal Transduction
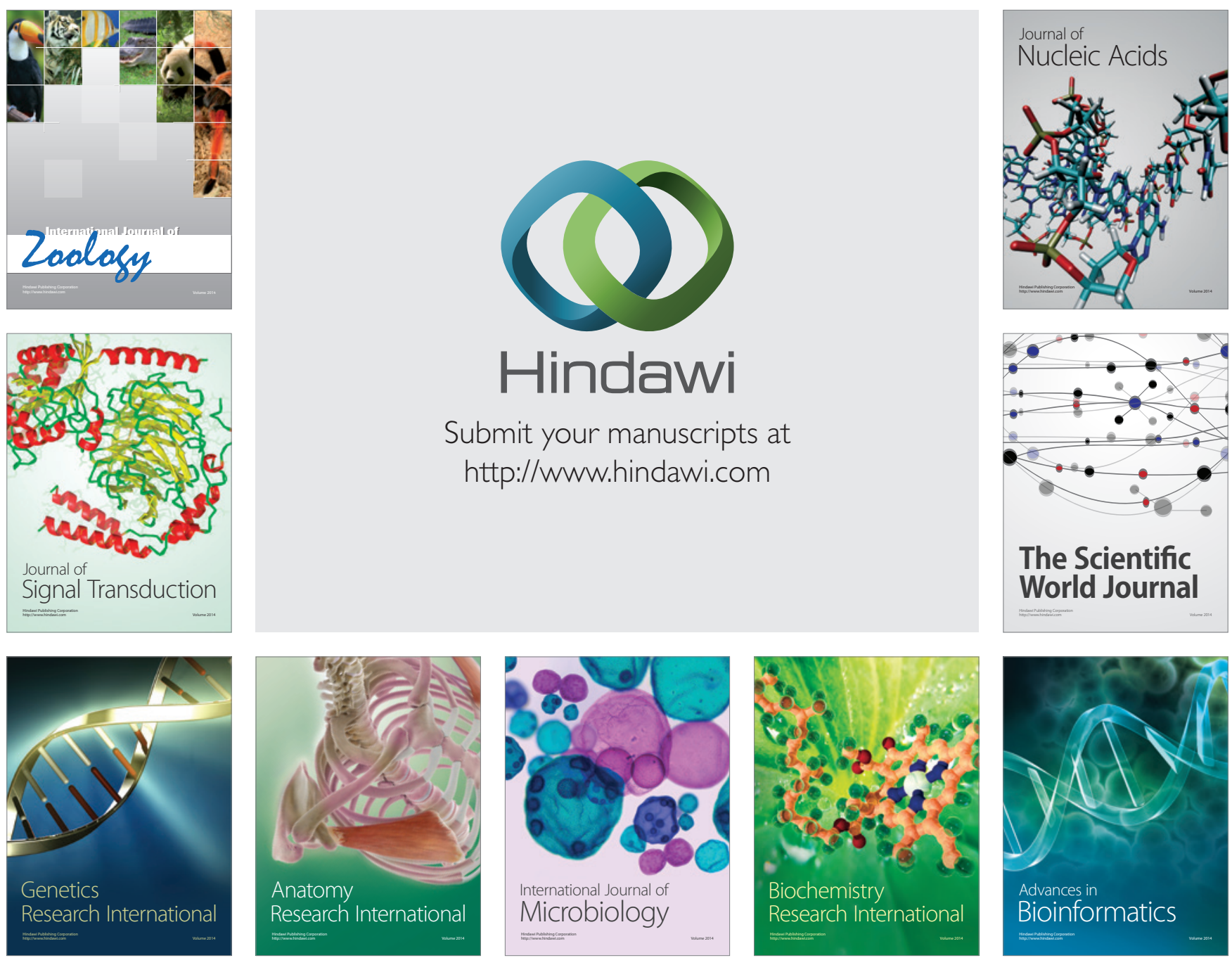

The Scientific World Journal
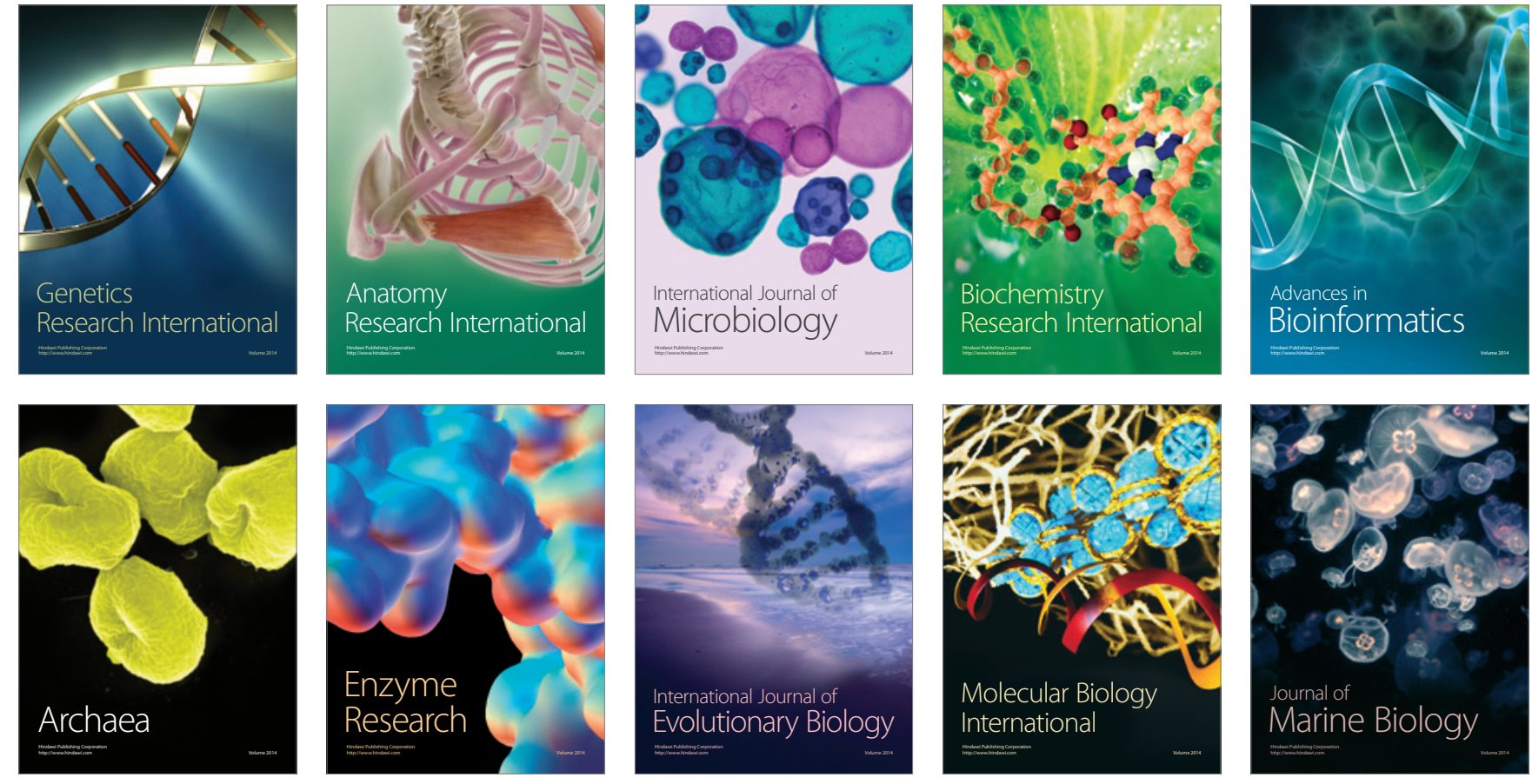